\title{
Comparison of optical-feedback cavity-enhanced absorption spectroscopy and gas chromatography for ground-based and airborne measurements of atmospheric $\mathrm{CO}$ concentration
}

\author{
Irène Ventrillard ${ }^{1}$, Irène Xueref-Remy ${ }^{2}$, Martina Schmidt ${ }^{2, a}$, Camille Yver Kwok ${ }^{2}$, Xavier Faïn ${ }^{3}$, and \\ Daniele Romanini ${ }^{1}$ \\ ${ }^{1}$ Univ. Grenoble Alpes, CNRS-UMR5588, Laboratoire Interdisciplinaire de Physique (LIPhy), Grenoble, France \\ ${ }^{2}$ Laboratoire des Sciences du Climat et de l'Environnement (LSCE), UMR CEA-CNRS 1572, Gif-sur-Yvette, France \\ ${ }^{3}$ Univ. Grenoble Alpes, Institut des Géosciences de l'Environnement (IGE), Grenoble, France \\ ${ }^{a}$ now at: Institut für Umweltphysik (IUP), Heidelberg University, Heidelberg, Germany
}

Correspondence to: Irène Ventrillard (irene.ventrillard@univ-grenoble-alpes.fr)

Received: 25 November 2016 - Discussion started: 19 December 2016

Revised: 27 March 2017 - Accepted: 12 April 2017 - Published: 16 May 2017

\begin{abstract}
We present the first comparison of carbon monoxide (CO) measurements performed with a portable laser spectrometer that exploits the optical-feedback cavity-enhanced absorption spectroscopy (OF-CEAS) technique, against a high-performance automated gas chromatograph (GC) with a mercuric oxide reduction gas detector (RGD). First, measurements of atmospheric $\mathrm{CO}$ mole fraction were continuously collected in a Paris (France) suburb over 1 week. Both instruments showed an excellent agreement within typically $2 \mathrm{ppb}$ (part per billion in volume), fulfilling the World Meteorological Organization (WMO) recommendation for $\mathrm{CO}$ inter-laboratory comparison. The compact size and robustness of the OF-CEAS instrument allowed its operation aboard a small aircraft employed for routine tropospheric air analysis over the French Orléans forest area. Direct OFCEAS real-time $\mathrm{CO}$ measurements in tropospheric air were then compared with later analysis of flask samples by the gas chromatograph. Again, a very good agreement was observed. This work establishes that the OF-CEAS laser spectrometer can run unattended at a very high level of sensitivity $(<1 \mathrm{ppb})$ and stability without any periodic calibration.
\end{abstract}

\section{Introduction}

Carbon monoxide $(\mathrm{CO})$ is a reactive trace gas that plays a significant role in global atmospheric chemistry by being a major sink of tropospheric hydroxyl radicals $(\mathrm{OH})$. Hydroxyl radical is the main tropospheric oxidant, thus its abundance affects the lifetimes of radiatively important gases such as methane. Oxidation of $\mathrm{CO}$ by $\mathrm{OH}$ also provides a source or a sink, respectively in high or low $\mathrm{NO}_{x}$ conditions, for tropospheric ozone (Logan et al., 1981). CO concentration in the atmosphere have, thus, crucial implications for both climate and air quality issues, and accurate $\mathrm{CO}$ measurements in the troposphere are important when modelling climatechemistry interactions with global coupled models (Voulgarakis et al., 2013).

Consequently, monitoring of tropospheric $\mathrm{CO}$ has been conducted over the last decades on the global scale (Novelli et al., 1998). Recently satellite-based observations have become an important contribution to regional monitoring of atmospheric CO (Worden et al., 2013). There is still a need, however, to strengthen direct $\mathrm{CO}$ observations from both surface stations and aircraft to assess the large spatio-temporal variability of $\mathrm{CO}$, especially within the boundary layer at the regional scale for a better understanding of atmospheric chemistry and transport, and to improve forecast modelling of air quality (Sahu et al., 2013; Warner et al., 2013; Té et al., 2016). 
Historical methods, such as gas chromatography, have been used for many years for surface monitoring of $\mathrm{CO}$ (Derwent et al., 2001; Langenfelds et al., 2002; Yver et al., 2009; Schmidt et al., 2014). A gas chromatograph (GC) equipped with a mercuric oxide reduction gas detector (RGD) allows for very sensitive laboratory measurements but requires hourly calibration procedures with calibration gases and an expert operator to achieve uniform high-quality results. In addition, the mercuric oxide reduction detectors are known for their non-linear response function, which needs to be quantified on a regular basis several times per year (Yver et al., 2009). On the other hand, recent developments in optical spectroscopy methods have brought new alternatives for in situ CO monitoring (Zellweger et al., 2012; Chen et al., 2013; Yver Kwok et al., 2015). The most sensitive optical techniques allow a detection limit at the ppb level and below. Among them, optical-feedback cavity-enhanced absorption spectroscopy (OF-CEAS; Morville et al., 2005) exploits a high-finesse optical cavity in which a laser source is coupled to enhance the interaction of photons with gas molecules present inside the cavity (Morville et al., 2014). OF-CEAS offers many advantages for quantitative and selective trace gas analysis: it allows real-time absolute measurements with the smallest detectable absorption coefficient in the range of a few $10^{-10} \mathrm{~cm}^{-1}$ for $1 \mathrm{~s}$ acquisition time (Landsberg et al., 2014), it does not require periodic calibrations with certified gas mixtures, its sampling volume is small $\left(20 \mathrm{~cm}^{3}\right)$, its response time can be faster than $1 \mathrm{~s}$, and it enables the development of compact instruments to be operated by nonspecialists.

Another advantage that follows from the high sensitivity of the OF-CEAS technique is the ability to work in the nearinfrared region (NIR), where widely used optics are commercially available together with room temperature lasers and detectors. Traditional near-infrared OF-CEAS instruments reach a limit of detection (LOD) at the sub-ppb level for CO (Faïn et al., 2014) that is comparable to other instruments exploiting the mid-infrared (MIR) spectral region where absorption coefficient are typically 2 orders of magnitude higher. Indeed, commercial MIR laser spectrometers based on different laser spectroscopy techniques offer $\mathrm{CO}$ sub-ppb LOD, such as Picarro instruments by cavity ring-down spectroscopy (CRDS), Los Gatos analysers by off-axis integrated cavity output spectroscopy (OA-ICOS) or instruments exploiting a multi-pass cell like the Aerodyne products. The performance of the OF-CEAS technique in the NIR led a private company (AP2E, Aix-en-Provence, France) to exploit the patent for commercially available analysers (namely ProCEAS). On the other hand, exploiting OF-CEAS in the MIR allows the reaching of sub-ppb levels for several species of interest in trace detection and ppm levels for isotopic ratio measurements (Maisons et al., 2010; Gorrotxategi-Carbajo et al., 2013; Manfred et al., 2016; Richard et al., 2016).

OF-CEAS-based measurements of $\mathrm{CO}$ have been conducted before around various applications, for example for in situ trace measurements on geothermal gases (Kassi et al., 2006), for continuous and high-resolution measurement of air extracted from ice cores drilled out of polar glaciers (Faïn et al., 2014), and for breath analysis in different medical settings (Ventrillard-Courtillot et al., 2009; Maignan et al., 2014). ProCEAS analysers are now commercialized in the domains of industrial and air quality monitoring, with some very stringent applications such as air quality control onboard nuclear submarines. In order to further establish for different user communities that OF-CEAS can become a work horse in many applications of $\mathrm{CO}$ analysis, which demand robust and compact instrumentation with ppb sensitivity and a fast response time, this paper reports on the comparison of $\mathrm{CO}$ measurements performed by OF-CEAS against those obtained by the well-established gas chromatography technique. GC measurements were done with a highperformance gas chromatograph equipped with a mercuric oxide reduction gas detector (Yver et al., 2009). First, the atmospheric CO concentration in Gif-sur-Yvette, France, was continuously analysed at ground level over 1 week. Then, the OF-CEAS instrument was set aboard a small aircraft employed for periodic tropospheric air measurements over the French Orléans forest area. Airborne in situ CO measurements by OF-CEAS were then compared with flask samples later analysed with the GC at LSCE.

All values reported in this paper are dry air mole fractions (expressed in ppm or ppb) but are called "concentrations" as commonly done by the community.

\section{Materials and methods}

We briefly describe the GC set-up and outline the OF-CEAS technique, highlighting the characteristics most relevant for the measurements reported here such as instruments calibrations. In particular two steps of post-data processing were needed to come to an excellent agreement between the optical and chromatographic measurements performed during autumn 2006. Firstly, the non-linearity of the GC reduction gas detector was corrected following a procedure established in 2010. Secondly, the two instruments had to be calibrated on the same standard scale from the World Meteorological Organization (WMO CO X2004). This was performed with a recent re-evaluation (in 2014) on this scale of the gas standards initially used for the OF-CEAS spectrometer calibration.

\subsection{Gas chromatograph}

The LSCE laboratory at Gif-sur-Yvette is equipped with two coupled gas chromatographs (HP-6890, Agilent and PP1, Peak Laboratories) which run fully automated, alternating between calibration gas and ambient air, in order to analyse $\mathrm{CO}, \mathrm{H}_{2}, \mathrm{CO}_{2}, \mathrm{CH}_{4}, \mathrm{~N}_{2} \mathrm{O}$ and $\mathrm{SF}_{6}$ concentration in atmospheric measurements, flask samples or high-pressure cylin- 
ders. Detailed descriptions of the GC system for $\mathrm{CO}$ analysis is given by Yver et al. (2009). CO is analysed with the PP1 chromatograph equipped with a reduction gas detector after reduction of mercuric oxide and detection of mercury vapour by UV absorption. Each analysis takes less than 6 min, allowing between two and six injections of ambient air alternating with calibration gases and flask samples. The air is dried before the injection in two steps. First, it passes through a glass trap which is hosted in a commercial refrigerator kept at $5{ }^{\circ} \mathrm{C}$ in order to remove a large fraction of water vapour, and in the second step air is further dried by passing through a second glass trap cooled in an ethanol bath at $-55^{\circ} \mathrm{C}$ using a cryogenic cooler (designed as the "cooling trap" in the following). An operator is only required to change the cooling trap 2-3 times per week and to restart the acquisition.

\subsection{Calibration of the gas chromatograph: correction of the reduction gas detector non-linearity}

The GC is calibrated for $\mathrm{CO}$ with cylinders certified by the NOAA Global Monitoring Division (GMD) on the WMO CO X2004 scale (Novelli et al., 1994). CO concentrations are calculated using regular measurements of one calibration cylinder with a typical atmospheric concentration value (here $168.0 \pm 0.8 \mathrm{ppb})$ and a non-linear correction function of the detector response as described in Yver et al. (2009) and Yver (2010). The correction function is determined on an annual frequency using a set of five cylinders with $\mathrm{CO}$ concentration ranges from $57 \pm 1.0 \mathrm{ppb}$ to $523 \mathrm{ppb} \pm 10.9 \mathrm{ppb}$ and applied as a post-run correction (Yver et al., 2009). This non-linear correction was validated using flask measurement comparisons between LSCE and NOAA, with a mean difference of $4.5 \pm 2.2 \mathrm{ppb}$ for the period of July 2006 to July 2009 . For the 1 week comparison campaign with the OF-CEAS instrument in November 2006, the correction function applied to CO in situ measurements by the $\mathrm{GC}\left(\mathrm{CO}_{\text {meas }}\right)$ to obtain the calibrated $\mathrm{CO}$ concentrations reported in the following is given by

$$
\begin{aligned}
\Delta \mathrm{CO}_{\text {corr }} & =11.4+0.077 \times \mathrm{CO}_{\text {meas }}-7.110^{-4} \\
& \times\left(\mathrm{CO}_{\text {meas }}\right)^{2}+1.0310^{-8} \times\left(\mathrm{CO}_{\text {meas }}\right)^{3} .
\end{aligned}
$$

It applies a correction for the non-linear behaviour of the analyser in the range of -15 to $+15 \mathrm{ppb}$ for measured $\mathrm{CO}$ concentration up to $500 \mathrm{ppb}$.

The calibration cylinder is analysed every $30-40 \mathrm{~min}$ along with a quality control gas, a so called target gas, with a $\mathrm{CO}$ concentration of $68 \mathrm{ppb}$, that is treated as unknown. Over the entire comparison period, the repeatability defined as $1 \sigma$ standard deviation of the target gas is $0.4 \mathrm{ppb}$.

The flask samples filled during the airborne campaign are measured in a similar way to the ambient air concentration with two injections per flask.

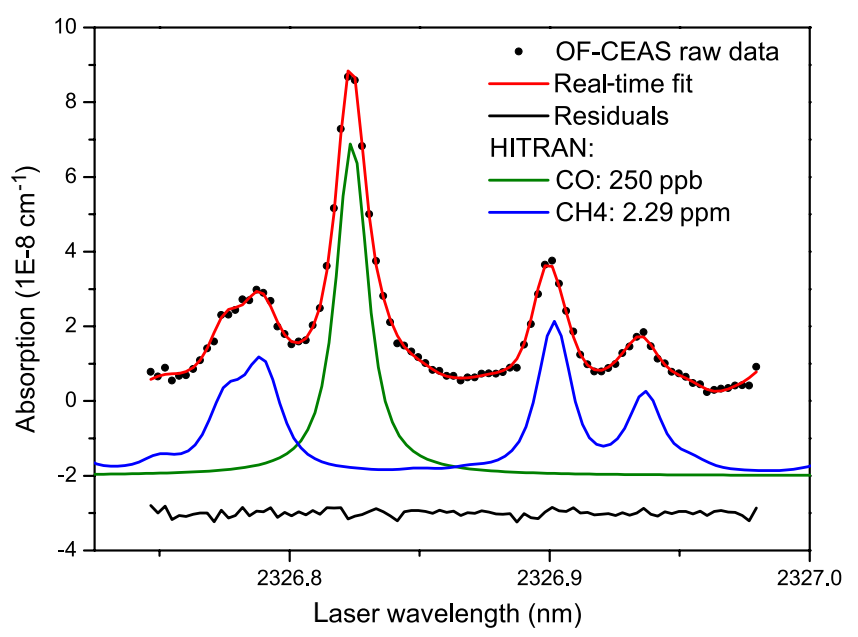

Figure 1. Single OF-CEAS spectra in absolute absorption units, recorded in $150 \mathrm{~ms}$ with a gas sample at a pressure of $200 \mathrm{mbar}$ and a temperature of $295 \mathrm{~K}$. CO and $\mathrm{CH}_{4}$ concentrations are deduced from the real-time fit. The standard deviation of the residuals is $9 \times 10^{-10} \mathrm{~cm}^{-1}$ (in absorption units). The base line has been subtracted for comparison with HITRAN-simulated absorption spectra (Rothman et al., 2013). HITRAN spectra and the residuals have been offset for clarity.

\subsection{Optical-feedback cavity-enhanced absorption spectrometer}

The laser spectroscopy technique going under the name of OF-CEAS was introduced by Morville et al. (2005) and has been further detailed in different publications (Kerstel et al., 2006; Kassi et al., 2006; Ventrillard-Courtillot et al., 2009; Faïn et al., 2014; Maignan et al., 2014; Morville et al., 2014). In particular the OF-CEAS instrument used in this study has been described in Kassi et al. (2006). It provides in situ CO measurements with a detection limit of $0.2 \mathrm{ppb}$ in $20 \mathrm{~s}$ (Faïn et al., 2014) with no calibration and running unattended. Here we will just recall the basic principle of OF-CEAS.

Spectroscopic measurements of trace gas concentrations require a long light absorption path. Like other spectroscopy techniques, OF-CEAS is based upon the use of a sample cell made with an optical cavity in order to enhance light interaction with the gas sample. Specifically in the spectrometer used here for $\mathrm{CO}$ monitoring, the resonant optical cavity composed of high-reflectivity mirrors (mirror reflectivity: $R \simeq 99.995 \%$ ) allows a $\sim 20 \mathrm{~km}$ effective absorption length with a compact set-up: the cavity is only $1 \mathrm{~m}$ long, folded to a $0.5 \mathrm{~m}$ external size. The difficulty of using a resonant cavity with high-reflectivity mirrors (thus very small transmissivity) resides in the coupling of a sufficient amount of light in the cavity by injecting laser light through one of the cavity mirrors. The originality of OF-CEAS is that the optical cavity is made of three mirrors placed in a "V-shaped" configuration. In this way, a fraction of the light trapped inside the optical cavity, and therefore frequency-selected by a resonant 
mode of the cavity, can be returned to the laser. The nonlinear response of the laser then forces it to lase on the exact frequency of the excited cavity mode. This optical-feedback effect is also responsible for a narrowing of the laser emission line width and an increase of the cavity transmission to a level that is orders of magnitude larger than in competing techniques (Morville et al., 2005). OF-CEAS absorption spectra are acquired on a small spectral region, as shown in Fig. 1 for the present case, by scanning the laser frequency at a relatively high repetition rate $(6 \mathrm{~Hz}$ here $)$. However, the measurement response time for $1 / e$ change in a concentration value is not limited by this rate but by the gas exchange rate inside the sample volume. Therefore, the cell is designed to allow minimal dead spaces and a small internal (sample) volume, which does not exceed $18 \mathrm{~cm}^{3}$. The gas is continuously flowing and the cell pressure is stabilized with a downstream pressure regulator to $200 \mathrm{mbar}$ in this study. The flow is adjusted manually with a needle valve at the inlet of the sampling cell to $250 \mathrm{sccm}$ (standard $\mathrm{cm}$ cubes per minute) for ground measurements and around $50 \mathrm{sccm}$ for airborne measurements. The corresponding gas exchange times are then 0.9 and $4.3 \mathrm{~s}$ respectively. If needed, a shorter response time can be obtained by using a lower sample pressure or a higher flow rate. The design of the spectrometer is robust and compact: the optical assembly and all the electronics, for realtime control and data acquisition, fit inside a 19 in chassis where the V-shaped cavity is placed in the diagonal as shown in Fig. 1 of Kassi et al. (2006). The device is temperature stabilized around $22^{\circ} \mathrm{C}$ using heating adhesive ribbons.

Importantly, OF-CEAS provides quantitative absorption measurements in real time without the need for a periodic calibration with certified gas mixtures. A normalization procedure of the absorbance scale is realized continuously based on cavity optical loss measurements performed by CRDS (Kerstel et al., 2006; Morville et al., 2014). Pressure and temperature stabilization of the sample inside the cavity allows for a real-time numerical fit of the measured absorption spectra with a reduced number of parameters (GorrotxategiCarbajo et al., 2013). This enables the selective determination of the concentrations of all compounds that possess absorption lines in the selected spectral window (CO and $\mathrm{CH}_{4}$ here). This is a key point in trace gas monitoring, with atmospheric air being a highly complex gas mixture. To optimize the CO detection limit, an NIR distributed-feedback diode laser is chosen emitting in the [2.3-2.4] $\mu \mathrm{m}$ range (Fig. 1), an interesting region that includes an atmospheric window where water vapour absorption lines are sparse and weak, while several light species such as CO display relatively strong absorption bands. The smallest detectable absorption coefficient is typically in the range of several $10^{-10} \mathrm{~cm}^{-1}$. As a result, an OF-CEAS instrument optimized for CO monitoring has an LOD of $0.2 \mathrm{ppb}$ of $\mathrm{CO}$ for an acquisition time of $20 \mathrm{~s}$, a value derived from an Allan variance study in Faïn et al. (2014).
Short response time and low LOD allow OF-CEAS instruments to perform fast trace gas monitoring. This has already been exploited in airborne atmospheric measurements of methane in Romanini et al. (2006), water isotopes in Iannone et al. (2009a) and Kerstel et al. (2006), and in other fields using laboratory prototypes and commercial instruments (ProCEAS) as mentioned in the introduction section.

\subsection{Calibration of the OF-CEAS spectrometer: conversion of absolute molecular absorption to $\mathrm{CO}$ concentration}

The ring-down calibration included in the OF-CEAS technique allows for direct absolute molecular absorption measurements (in $\mathrm{cm}^{-1}$ unit, Fig. 1). Then line intensity is directly converted to $\mathrm{CO}$ concentration with a conversion factor specific to the fitted absorption line for the temperature and pressure operation conditions $(298.5 \pm 1 \mathrm{~K}$ and $200 \pm 1.8$ mbar in this work). This allows to account for temperature and pressure effects on the line intensity parameters. It is important to stress that this factor is a constant that does not depend on the cavity finesse (continuously measured by ring-down) nor on the gas sample composition (the multiline fit allows independent fit of each species) as far as the foreign pressure broadening effect on $\mathrm{CO}$ absorption lines from water can be neglected. This is justified for atmospheric measurements where water concentration remains small (it varies from 0.8 to $1.6 \%$ for ground-based measurements reported in this work). As a consequence, the conversion factor of each molecule needs to be determined for the OF-CEAS spectrometer working conditions only once, and then during operation the instrument delivers absolute concentrations in real time without the need of any calibration with certified mixtures.

The conversion factor can be derived from a spectral database or by direct calibration using certified mixtures. Even if the line intensities for $\mathrm{CO}$ in this spectral region are well defined to better than $1 \%$ in the high-resolution transmission molecular absorption (HITRAN) database (Li et al., 2015), in practice calibration with gas standards is found to be more accurate because it cancels sensors pressure and temperature absolute accuracy and allows the minimizing of line profile effects by considering a specific model in the fit procedure - a Rautian model is used as in GorrotxategiCarbajo et al. (2013).

For the comparison campaign in 2006, the OF-CEAS spectrometer was calibrated with two high-pressure cylinders containing air whose $\mathrm{CO}$ concentration had been certified in 1995 by the Commonwealth Scientific and Industrial Research Organisation (CSIRO). However, the GC was calibrated on the WMO X2004 scale provided by the NOAA. Differences between CSIRO and NOAA CO scales on the order of $6 \mathrm{ppb}$ have been reported by Masarie et al. (2001). Therefore, we re-evaluated $\mathrm{CO}$ concentrations in the CSIRO cylinders against the WMO CO X2004 scale. This was 
done in 2014 using another OF-CEAS instrument designed for ice core analysis (Faïn et al., 2014). This instrument was calibrated with three standards certified in 2011 by the NOAA GMD Carbon Cycle Group on the WMO CO X2004 scale $(33.2 \pm 0.5,51.8 \pm 0.1$ and $102.1 \pm 0.1 \mathrm{ppb}$ of $\mathrm{CO})$. The two working standards used to calibrate the instrument for the 2006 campaign were recalibrated to $35.0 \pm 1.5$ and $104.0 \pm 1.5 \mathrm{ppb}$, while the CSIRO values certified in 1995 were $32.6 \pm 0.7$ and $98.7 \pm 1 \mathrm{ppb}$, respectively.

These WMO-scaled CO standard gas values were then used to calibrate the entire 2006 dataset using a linear relationship (i.e., without offset adjustment), which is consistent with the fact that the zero of the spectral measurements is intrinsically accurate. Furthermore, the high linearity of OF-CEAS was previously reported for concentrations ranging over more than three decades (data published for water measurements in Iannone et al., 2009b). The accuracy of this calibration is estimated to be of $2 \%$, limited by the accuracy of the NOAA standards. However, the obtained conversion factor corresponds to a $10 \%$ overestimation of the line intensity specified in HITRAN with a $1 \%$ accuracy. CSIRO specifications of the two standards being offset by 5 and $7 \%$ as compared to NOAA standards are not compatible with the HITRAN database. Nonetheless, the good agreement of OF-CEAS and GC measurements reported in the following shows that this calibration on the same reference scale is a crucial point for the inter-comparison.

The LOD of the OF-CEAS spectrometer is much smaller than the accuracy of the NOAA standards, at the level of $0.2 \mathrm{ppb}$ for an acquisition time of $20 \mathrm{~s}$. At longer acquisition times, small drifts prevent a better averaging. It is partly attributed to drifts in the sensors that are used to control sample pressure and temperature, and thus the selection of more stable sensors can decrease the drift. Other causes of drift are changes in parasitic optical etalon effects (Morville et al., 2014). However, the drifts associated with these optical effects can be made quite small and cannot increase arbitrarily and remain bounded at all times as shown by the Allan variance of CO measurements in Faïn et al. (2014).

\section{Comparison: results and discussion}

\subsection{In situ ground measurements}

Direct comparison of atmospheric $\mathrm{CO}$ concentration measurements by GC and OF-CEAS over 1 week (8-14 November 2006) was performed at LSCE in Gif-sur-Yvette, $20 \mathrm{~km}$ southwest of Paris $\left(48^{\circ} 43^{\circ \circ} \mathrm{N}, 02^{\circ} 09^{\circ} \mathrm{E} ; 120 \mathrm{~m}\right.$ above sea level). The GC set-up routinely monitors atmospheric concentration with a sampling inlet located on the roof of the LSCE building, $7 \mathrm{~m}$ above ground level. The OF-CEAS instrument from LIPhy was set to run in the same building but with an independent sampling line. Sampling lines measured about $20 \mathrm{~m}$ and were made of $3 / 8$ in diameter Dekabon tubes.
The estimated sample propagation delay along the tube from the roof to the OF-CEAS instrument is about $6 \mathrm{~min}$ (with a gas flow of $250 \mathrm{sccm}$ ). A larger delay is observed on the GC data due to the use of the cold trap. The volume of this trap corresponds to the sample volume collected over about 15 min by the GC, inducing a smoothing of the signal of the semi-continuous injections. To eliminate the time delay between both instruments, the time shift was fixed to $14 \mathrm{~min}$ (Fig. 2).

Reported GC CO concentrations are dry air mole fractions. For the comparison, the OF-CEAS CO mole fraction $\left(x_{\mathrm{CO}, \text { air }}\right)$ is converted into dry air mole fraction $\left(x_{\mathrm{CO}, \mathrm{dry}}\right)$ according to

$x_{\mathrm{CO}, \mathrm{dry}}=\frac{x_{\mathrm{CO}, \text { air }}}{1-x_{\mathrm{H}_{2} \mathrm{O}}}=\frac{x_{\mathrm{CO}, \text { air }}}{1-[\mathrm{RH} \times e(T)] / P}$,

where the water mole fraction $\left(x_{\mathrm{H}_{2} \mathrm{O}}\right)$ is computed from the relative humidity rate $(\mathrm{RH})$, the atmospheric pressure $(P)$ and the water saturation vapour pressure $(e(T))$ given by a polynomial function of the atmospheric temperature $(T$; Lowe, 1976). The meteorological data used (RH, $P$ and $T$ ) are routinely monitored at the Saclay radar located about $1.5 \mathrm{~km}$ north-northwest from the sampling point (data provided by the SPR group from Saclay CEA).

OF-CEAS and GC raw data were post-treated as detailed in Sect. 2. In Fig. 2 the typical variations of atmospheric $\mathrm{CO}$ dry concentration measured by both the GC and the OF-CEAS analysers during a weekday (Fig. 2a), a Sunday (Fig. 2b) and a Wednesday night (Fig. 2c) are shown. During night-time and most of the day on the weekends, CO concentration slowly varies within typically 100-300 ppb. But during weekdays emissions from nearby traffic usually induce two rush hour peaks in the morning at around 08:00 local time (LT) and in the evening after 17:00 LT. The persistence and higher intensity of the second $\mathrm{CO}$ peak could be related to air mass change or to the Friday evening traffic jams all around the Paris suburbs (Fig. 2a). During daytime and in the evening, the fast response time of the OF-CEAS instrument ( $1 \mathrm{~s}$ averaged here to $2 \mathrm{~s}$ ) allows the recording of many short but very strong peaks (sometime rising up to more than $1 \mathrm{ppm}$ for only 1 or $2 \mathrm{~min}$ ). These are due to local pollution of vehicles passing by the laboratory. The 14 November 2006 night (Fig. 2c) is characterized by the fact that CO concentration remains quite stable around $100 \mathrm{ppb}$ (concentration fluctuations smaller than $20 \mathrm{ppb}$ are measured over $7 \mathrm{~h}$ ), thus allowing a comparison over several hours with nearly no effect from the slower GC response time.

Overall, OF-CEAS and GC measurements show an excellent agreement. When $\mathrm{CO}$ concentration varies slowly, such as during night-time and Sunday measurements shown in Fig. 2, the agreement is within about $2 \mathrm{ppb}$ rms over several hours for concentration values ranging from 100 to $300 \mathrm{ppb}$ for the whole comparison period of 1 week. This difference is fully compatible with the calibration accuracy of the two instruments reported before. When CO concentration is sub- 

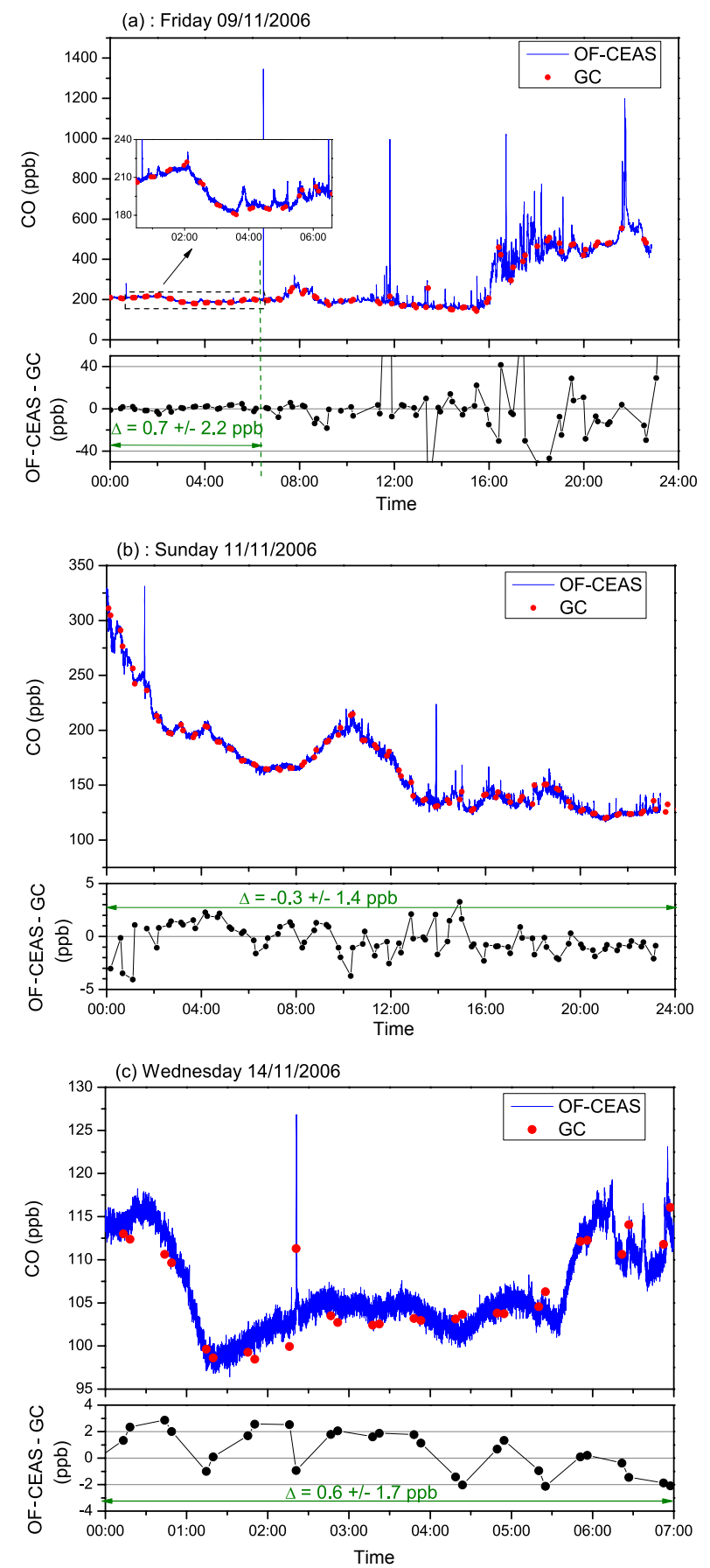

Figure 2. Two days and one night monitoring of atmospheric concentration in Gif-sur-Yvette selected for their different ranges. CO values are given in dry air mole fraction. The GC data are timeshifted by $14 \mathrm{~min}$ in order to eliminate the time delay between the two instruments. Upper graphs in each panel: OF-CEAS measurements are averaged for $2 \mathrm{~s}$ while GC measurements are performed twice an hour. Lower graphs in each panel: difference of the measurements after averaging OF-CEAS data for 1 minute around the GC time measurement. Mean values of the difference and standard deviations are written in green. ject to fast changes such as in Fig. 2a, the strong difference in the GC and OF-CEAS measurements is explained by the slower response time of the GC instrument due to the buffering effect of the cooling trap. The air sample is continuously flushed in the cooling trap, and the effect on CO concentration measurements by the $\mathrm{GC}$ is not equivalent to a simple time average. A more complex weighted moving average could be performed on the faster OF-CEAS measurement to try to mimic the GC measurement, but a study concerning this averaging issue appears to be beyond the scope of this paper.

The OF-CEAS instrument measures $\mathrm{CO}$ and $\mathrm{CH}_{4}$ simultaneously (Fig. 1). Contrary to $\mathrm{CO}, \mathrm{CH}_{4}$ concentration is not sensitive to traffic pollution. Its daily variability is usually less than $10 \%$, with a background value of about $1900 \mathrm{ppb}$. The rms noise of the OF-CEAS measurements for $\mathrm{CH}_{4}$ is $4 \mathrm{ppb}$ for an averaging time of $20 \mathrm{~s}$. A good agreement between OF-CEAS and GC is also found with maximum deviations of $\pm 20 \mathrm{ppb}$, corresponding to about $1 \%$ in relative units. Such performance has been previously reported in Romanini et al. (2006) with a similar OF-CEAS instrument compared to the same GC.

\subsection{Airborne measurements}

In the framework of the French RAMCES observation network for greenhouse gas monitoring, regular weekly flights have been carried out by LSCE since 1996 above the Orléans forest, located about $100 \mathrm{~km}$ south of Gif-sur-Yvette. This flight program aims to improve our understanding of transport processes into the atmospheric boundary layer and to better assess the relative role of local, regional and continental anthropogenic and biospheric fluxes on the observed trace gas concentrations. In particular, vertical profiles of trace gases are very useful for assessing atmospheric transport model performances. During the flights, air samples are collected in flasks, as described in Chevalier et al. (2009), and later analysed at LSCE by GC to measure the concentration of $\mathrm{CO}_{2}, \mathrm{CH}_{4}, \mathrm{CO}, \mathrm{N}_{2} \mathrm{O}$ and $\mathrm{SF}_{6}$ (Xueref-Remy et al., 2011; Haszpra et al., 2012). Glass flasks are filled at 10 different altitudes (between 100 and $3000 \mathrm{~m}$ above ground level). Those used for the present comparison were analysed 1 week after collection. On 15 November 2006, the OF-CEAS instrument was installed inside the aircraft to perform in situ measurements of atmospheric $\mathrm{CO}$ concentration during the entire flight. The OF-CEAS instrument was mounted in a 19 in rack fixed in place of a seat.

Tropospheric air was sampled upwind of the aircraft engine exhaust: a $2 \mathrm{~m}$ Dekabon inlet line carried outside air to the set-up entrance, passing through a customized window of the aircraft. The same inlet was used for the OF-CEAS instrument. Regarding the flasks set up, the sampling unit consisted of a diaphragm pump which drew air through a chemical drying cartridge filled with $\mathrm{Mg}\left(\mathrm{ClO}_{4}\right)_{2}$. Air was collected in $1 \mathrm{~L}$ glass flasks sealed with PTFE O-rings. Flasks were 

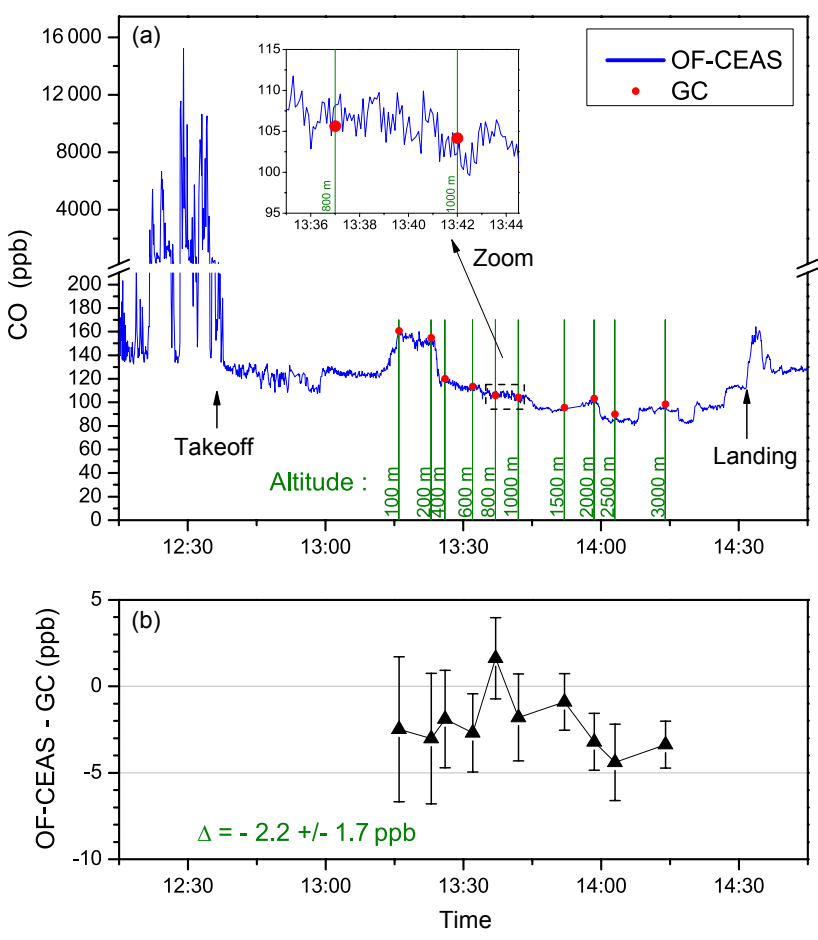

Figure 3. (a) CO airborne measurements by OF-CEAS in real time and by GC with latter flask analysis at the LSCE. Altitudes are indicated during collection sample for GC measurements. OF-CEAS data are averaged for $5.5 \mathrm{~s}$. (b) Difference between OF-CEAS and GC measurements, where OF-CEAS values are computed in dry air and averaged for $1 \mathrm{~min}$ around the flask filling times. Error bars in this graph indicate the standard deviation of OF-CEAS measurements for $1 \mathrm{~min}$ around the comparison time. The difference of OFCEAS and GC measurements has a mean value of $-2.2 \mathrm{ppb}$ with a standard deviation of $1.7 \mathrm{ppb}$.

collected in pairs and pressurized to 2 bar absolute pressure. The filling step took between $30 \mathrm{~s}$ and $1 \mathrm{~min}$, during which the plane covered a typical horizontal distance of $5 \mathrm{~km}$.

The entire set of measurements is shown in Fig. 3 starting from the airport of Toussus-le-Noble $\left(48^{\circ} 45^{\prime \circ} \mathrm{N}, 2^{\circ} 08^{\circ}{ }^{\circ} \mathrm{E}\right.$; $164 \mathrm{~m}$ a.s.1.), during the flight to the Orléans forest area $\left(47^{\circ} 50^{\prime \circ} \mathrm{N}, 2^{\circ} 30^{\prime \circ} \mathrm{E} ; 135 \mathrm{~m}\right.$ a.s.l. $)$ where the plane starts a routine flight that consists of legs at the 10 pre-defined altitudes for the flask samples collection, and during the flight back to the airport. During the flight above the Orléans forest, CO concentrations remained at around $90 \mathrm{ppb}( \pm$ $10 \mathrm{ppb}$ ) above $1000 \mathrm{~m}$, while an increase at lower altitudes was clearly measured up to $150 \mathrm{ppb}$ at $100 \mathrm{~m}$ due to surface $\mathrm{CO}$ sources like traffic and heating.

It should be noted that the OF-CEAS instrument is robust enough to operate in the harsh environment of a small aircraft including during takeoff and landing phases. On the tarmac, $\mathrm{CO}$ rises up to $16 \mathrm{ppm}$ due to airplane exhaust gases. This illustrates the wide sensitivity range of the measurements, of about 4 orders of magnitude. During the whole flight, the instrument ran unattended. The only not automatized action by the operator required during the flight consisted of adjusting the flow in the sampling cell with a needle valve. Given that this valve was placed at instrument inlet, the flow changed linearly with pressure, thus decreased with altitude. However, for GC comparison, measurements were taken during constant altitude sections, allowing averaging on time scales largely exceeding the sample exchange time for flow around $50 \mathrm{sccm}$. Later, flow regulation was automatized using a numerically controlled flow regulator. During the flight, the flow was slowly varying between 40 and $70 \mathrm{sccm}$. OFCEAS data were averaged for $5.5 \mathrm{~s}$ to be consistent with the largest value of the response time. It corresponds to a space resolution of $300 \mathrm{~m}$ according to the aircraft velocity. Due to the harsh environment in the plane, the standard deviation of the measurements was increased to typically $2 \mathrm{ppb}$ (zoom in Fig. 3), while for ground-based measurements it was $0.6 \mathrm{ppb}$ for $2 \mathrm{~s}$ averaging time (Fig. 2c).

As explained in the previous sections, for the comparison of GC and OF-CEAS measurements, post-data processing was performed to correct for the RGD non-linearity and to bring both instruments on the same calibration scale. Additionally, OF-CEAS concentrations have to be expressed in dry air. The water mole fraction was not monitored during the flight but was derived from a model allowing the computing of the specific humidity $q$ from meteorological data (analysis from the European Centre for Medium-Range Weather Forecasts, ECMWF). Water mole fraction is then given by

$x_{\mathrm{H}_{2} \mathrm{O}}=\frac{q \times M_{\text {dry }}}{M_{\mathrm{H}_{2} \mathrm{O}}+q \times\left(M_{\text {dry }}-M_{\mathrm{H}_{2} \mathrm{O}}\right)}$,

where $M_{\mathrm{H}_{2} \mathrm{O}}$ and $M_{\mathrm{dry}}$ are respectively the molar mass of water and dry air. During the flight, the values obtained for the water mole fraction varied typically from 0.2 to $1 \%$ at respectively high and low altitude, inducing a correction on $\mathrm{CO}$ values between +0.2 and $+1.6 \mathrm{ppb}$. The model was compared to the meteorological data $(\mathrm{RH}, P$ and $T$ ) provided by the closest station that is the radio sounding of Trappes $\left(48^{\circ} 46^{\prime \circ} \mathrm{N}, 2^{\circ} 1^{\prime \circ} \mathrm{E} ; 168 \mathrm{~m}\right.$ a.s.l.). These data were recorded by Meteo-France and are available on the SIRTA website at http://sirta.ipsl.polytechnique.fr/sirta. old/data_policy.html. Humidity rates derived from ECWMF model and Trappes data are in agreement within $20 \%$, which means that corrections obtained from one or the other model will be closer than the measurement error.

In the bottom of Fig. 3 the difference between OF-CEAS and GC CO concentration measurements is plotted. To be consistent with the typical filling duration of the flasks, OFCEAS values were averaged for $1 \mathrm{~min}$ around the flask filling times. A good agreement is obtained for the set of 10 measurements recorded at different altitudes, the difference has a mean value of $-2.2 \mathrm{ppb}$ with a standard deviation of $1.7 \mathrm{ppb}$. This small systematic difference could not be explained even when different artefacts like a residual effect of the non-linearity of the RGD or the humidity correction of 
the OF-CEAS measurements were examined. The agreement between the OF-CEAS spectrometer and the GC measurements is very close to the 2015 World Meteorological Organization compatibility goal of $1 \sigma$ for $\mathrm{CO}$ that is $\pm 2 \mathrm{ppb}$ (see WMO-GMA report edited by Tans and Zellweger, 2016).

\section{Conclusions}

The OF-CEAS technique allows for the development of sensitive, compact, robust and reliable instruments to perform in situ trace gas analysis. After a single calibration with a reference standard, an OF-CEAS instrument delivers in real-time absolute $\mathrm{CO}$ concentrations that are in excellent agreement over 1 week with a state-of-the-art gas chromatograph referenced to the same calibration scale. Similar performance is expected on other trace molecules for which sufficiently strong absorption lines are available. To reach the best accuracy, the GC is periodically calibrated with a standard gas every $30 \mathrm{~min}$ and is corrected from the RGD non-linearity with data post-processing. The agreement between the OFCEAS spectrometer and the GC for CO concentrations is typically better than $2 \mathrm{ppb}$, which meets the $2015 \mathrm{WMO}$ recommendation for CO inter-laboratory comparison (Tans and Zellweger, 2016). This agreement shows that OF-CEAS instrumental drift over the long term remains acceptable at the level of accuracy required for atmospheric $\mathrm{CO}$ monitoring. Periodic calibrations with a standard gas could become necessary to attain a higher degree of accuracy, since these calibrations could be used to correct the effect of these small drifts.

OF-CEAS instruments offer other advantages that are rarely associated with high sensitivity and selectivity in gas analysis. The sample volume inside the cavity is bellow $20 \mathrm{~cm}^{3}$ (standard temperature and pressure conditions), and the pressure can be lowered down to a few mbar, opening field applications in trace detection where small volume samples are available, such as bubbles of gas trapped in ice cores for climate studies (Faïn et al., 2014; Rhodes et al., 2016; Grilli et al., 2014). Additionally, some OF-CEAS analysers can reach a high sensitivity (below $1 \mathrm{ppb}$ for $\mathrm{CO}$ ) associated with a short response time (of typically $1 \mathrm{~s}$ ) that can be exploited in different applications such as in breath analysis to distinguish the respiratory phases (Ventrillard-Courtillot et al., 2009; Maignan et al., 2014) or during tropospheric and stratospheric airborne campaigns to deliver high spatial resolution data for atmospheric models (Romanini et al., 2006; Iannone et al., 2009a). OF-CEAS gas analysers are now commercialized by AP2E (ProCEAS), which offers presently the ability to measure the concentration of 15 molecular species at high sensitivity with high selectivity.

In order to further enhance the development of the OFCEAS technique in trace detection and isotopic ratio measurements, the spectral regions that can be exploited have been enlarged to allow new specific molecular absorption signatures. It has been demonstrated that this technique is compatible with different kinds of semiconductor lasers. Indeed, while OF-CEAS was previously developed in the NIR with distributed feedback telecom diode lasers (Morville et al., 2005; Kassi et al., 2006), it has been demonstrated that it is compatible with extended cavity diode lasers that operate in the visible (Courtillot et al., 2006; Horstjann et al., 2014) and with quantum cascade lasers (Maisons et al., 2010; Gorrotxategi-Carbajo et al., 2013) as well as more recently with interband cascade lasers (Manfred et al., 2015; Richard et al., 2016) in the mid-infrared region.

Data availability. Please contact the corresponding author, Irène Ventrillard (irene.ventrillard@univ-grenoble-alpes.fr).

Competing interests. The authors declare that they have no conflict of interest.

Acknowledgements. The authors are grateful to the whole RAMCES team for its participation in the flights. This work was partly funded by the CarboEurope-IP EU project and supported by the LabexOSUG@2020 program.

Edited by: M. von Hobe

Reviewed by: two anonymous referees

\section{References}

Chen, H., Karion, A., Rella, C. W., Winderlich, J., Gerbig, C., Filges, A., Newberger, T., Sweeney, C., and Tans, P. P.: Accurate measurements of carbon monoxide in humid air using the cavity ring-down spectroscopy (CRDS) technique, Atmos. Meas. Tech., 6, 1031-1040, doi:10.5194/amt-6-1031-2013, 2013.

Chevalier, F., Engelen, R. J., Carouge, C., Conway, T. J., Peylin, P., Pickett-heaps, C., Ramonet, M., and Rayner, P. J.: AIRS-based versus flask-based estimation of carbon surface fluxes, J. Geophys. Res., 114, D20303, doi:10.1029/2009JD012311, 2009.

Courtillot, I., Morville, J., Motto-Ros, V., and Romanini, D.: Sub$\mathrm{ppb} \mathrm{NO}_{2}$ detection by optical feedback cavity-enhanced absorption spectroscopy with a blue diode laser, Appl. Phys. B, 85, 407412, doi:10.1007/s00340-006-2354-3, 2006.

Derwent, R. G., Ryall, D. B., Jennings, S. G., Spain, T. G., and Simmonds, P. G.: Black carbon aerosol and carbon monoxide in European regionally polluted air masses at Mace Head, Ireland during 1995-1998, Atmos. Environ., 35, 6371-6378, doi:10.1016/S1352-2310(01)00394-6, 2001.

Faïn, X., Chappellaz, J., Rhodes, R. H., Stowasser, C., Blunier, T., McConnell, J. R., Brook, E. J., Preunkert, S., Legrand, M., Debois, T., and Romanini, D.: High resolution measurements of carbon monoxide along a late Holocene Greenland ice core: evidence for in situ production, Clim. Past, 10, 987-1000, doi:10.5194/cp-10-987-2014, 2014.

Gorrotxategi-Carbajo, P., Fasci, E., Ventrillard, I., Carras, M., Maisons, G., and Romanini, D.: Optical-feedback cavity- 
enhanced absorption spectroscopy with a quantum-cascade laser yields the lowest formaldehyde detection limit, Appl. Phys. B, 110, 309-314, doi:10.1007/s00340-013-5340-6, 2013.

Grilli, R., Marrocco, N., Desbois, T., Guillerm, C., Triest, J., Kerstel, E., and Romanini, D.: Invited Article : SUBGLACIOR : An optical analyzer embedded in an Antarctic ice probe for exploring the past climate, Rev. Sci. Instrum., 85, 1-7, doi:10.1063/1.4901018, 2014.

Haszpra, L., Ramonet, M., Schmidt, M., Barcza, Z., Pátkai, Zs., Tarczay, K., Yver, C., Tarniewicz, J., and Ciais, P.: Variation of $\mathrm{CO}_{2}$ mole fraction in the lower free troposphere, in the boundary layer and at the surface, Atmos. Chem. Phys., 12, 8865-8875, doi:10.5194/acp-12-8865-2012, 2012.

Horstjann, M., Andrés Hernández, M. D., Nenakhov, V., Chrobry, A., and Burrows, J. P.: Peroxy radical detection for airborne atmospheric measurements using absorption spectroscopy of NO2, Atmos. Meas. Tech., 7, 1245-1257, doi:10.5194/amt-7-12452014, 2014.

Iannone, R. Q., Kassi, S., Jost, H.-J., Chenevier, M., Romanini, D., Meijer, H. a. J., Dhaniyala, S., Snels, M., and Kerstel, E. R. T.: Development and airborne operation of a compact water isotope ratio infrared spectrometer., Isotopes in environmental and health studies, Isotopes in environmental and health studies, 45, 30320, doi:10.1080/10256010903172715, 2009a.

Iannone, R. Q., Romanini, D., Kassi, S., Meijer, H. a. J., and Kerstel, E. R. T.: A Microdrop Generator for the Calibration of a Water Vapor Isotope Ratio Spectrometer, J. Atmos. Ocean. Technol., 26, 1275-1288, doi:10.1175/2008JTECHA1218.1, 2009b.

Kassi, S., Chenevier, M., Gianfrani, L., Salhi, A., Rouillard, Y., Ouvrard, A., and Romanini, D.: Looking into the volcano with a Mid-IR DFB diode laser and Cavity Enhanced Absorption Spectroscopy, Optics Express, 14, 11442-11452, 2006.

Kerstel, E., Iannone, R., Chenevier, M., Kassi, S., Jost, H.-J., and Romanini, D.: A water isotope ( $2 \mathrm{H}, 17 \mathrm{O}$, and $18 \mathrm{O})$ spectrometer based on optical feedback cavity-enhanced absorption for in situ airborne applications, Appl. Phys. B, 85, 397-406, doi:10.1007/s00340-006-2356-1, 2006.

Landsberg, J., Romanini, D., and Kerstel, E.: Very high finesse optical-feedback cavity-enhanced absorption spectrometer for low concentration water vapor isotope analyses, Optics Letters, 39, 1795-1798, doi:10.1364/OL.39.001795, 2014.

Langenfelds, R. L., Francey, R. J., Pak, B. C., Steele, L. P., Lloyd, J., Trudinger, C. M., and Allison, C. E.: Interannual growth rate variations of atmospheric $\mathrm{CO} 2$ and its $\delta 13 \mathrm{C}, \mathrm{H}_{2}, \mathrm{CH}_{4}$, and CO between 1992 and 1999 linked to biomass burning, Global Biogeochem. Cy., 16, 21-1-21-22, doi:10.1029/2001GB001466, 2002.

Li, G., Gordon, I. E., Rothman, L. S., Tan, Y., Hu, S.-M., Kassi, S., Campargue, A., and Medvedev, E. S.: Rovibrational Line Lists for Nine Isotopologues of the Co Molecule in the X $1 \Sigma+$ Ground Electronic State, The Astrophysical Journal Supplement Series, 216, 15, doi:10.1088/0067-0049/216/1/15, 2015.

Logan, J. a., Prather, M. J., Wofsy, S. C., and Mcelroy, M. B.: Tropospheric chemistry - A global perspective, J. Geophys. Res., 86, 7210-7254, 1981.

Lowe, P.: An Approximating Polynomial for the Computation of Saturation Vapor Pressure, J. Appl. Meteorol., 16, 100-103, doi:10.1175/1520-0450(1978)017<0413:COAPFT>2.0.CO;2, 1976.
Maignan, M., Briot, R., Romanini, D., Gennai, S., HazanePuch, F., Brouta, A., Debaty, G., and Ventrillard, I.: Realtime measurements of endogenous carbon monoxide production in isolated pig lungs, J. Biomed. Opt., 19, 047001, doi:10.1117/1.JBO.19.4.047001, 2014.

Maisons, G., Gorrotxategi-Carbajo, P., Carras, M., and Romanini, D.: Optical-feedback cavity-enhanced absorption spectroscopy with a quantum cascade laser, Opt. Lett., 35, 3607-3609, 2010.

Manfred, K. M., Ritchie, G. A. D., Lang, N., Röpcke, J., and van Helden, J. H.: Optical feedback cavity-enhanced absorption spectroscopy with a $3.24 \mu \mathrm{m}$ interband cascade laser, Appl. Phys. Lett., 106, 221106, doi:10.1063/1.4922149, 2015.

Manfred, K. M., Hunter, K. M., Ciaffoni, L., and Ritchie, G. A. D.: ICL based OF-CEAS: a sensitive tool for analytical chemistry, Anal. Chem., 89, 902-909, doi:10.1021/acs.analchem.6b04030, 2016.

Masarie, K. A., Langenfelds, R. L., Allison, C. E., Conway, T. J., Dlugokencky, E. J., Francey, R. J., Steele, L. P., and Vaughn, B.: NOAA/CSIRO Flask Air Intercomparison Experiment : A strategy for directly assessing consistency among atmospheric measurements made by independent laboratories, J. Geophys. Res., 106, 20445-20464, 2001.

Morville, J., Kassi, S., Chenevier, M., and Romanini, D.: Fast, lownoise, mode-by-mode, cavity-enhanced absorption spectroscopy by diode-laser self-locking, Appl. Phys. B, 80, 1027-1038, doi:10.1007/s00340-005-1828-z, 2005.

Morville, J., Romanini, D., and Kerstel, E.: Cavity enhanced Absorption Spectroscopy with Optical Feedback, in: CavityEnhanced Spectroscopy and Sensing, edited by: Gagliardi, G. and Loock, H.-P., Springer-Verlag, Berlin Heidelberg, 163-207, doi:10.1007/978-3-642-40003-2, 2014.

Novelli, P. C., Collins, J. E., Myers, R. C., Sachse, G. W., and Scheep, H. E.: Reevaluation of the NOAA/CMDL carbon monoxide reference scale and comparisons with $\mathrm{CO}$ reference gases at NASA-Langley and the Fraunhofer Institut, J. Geophys. Res.-Atmos., 99, 12833-12839, 1994.

Novelli, P. C., Masarie, K. A., and Lang, P. M.: Distributions and recent changes of carbon monoxide in the lower troposphere, J. Geophys. Res., 103, 19015, doi:10.1029/98JD01366, 1998.

Rhodes, R. H., Faïn, X., Brook, E. J., McConnell, J. R., Maselli, O. J., Sigl, M., Edwards, J., Buizert, C., Blunier, T., Chappellaz, J., and Freitag, J.: Local artifacts in ice core methane records caused by layered bubble trapping and in situ production: a multi-site investigation, Clim. Past, 12, 1061-1077, doi:10.5194/cp-12-10612016, 2016.

Richard, L., Ventrillard, I., Chau, G., Jaulin, K., Kerstel, E., and Romanini, D.: Optical-feedback cavity- enhanced absorption spectroscopy with an interband cascade laser: application to $\mathrm{SO} 2$ trace analysis, Appl. Phys. B, 122, 247, doi:10.1007/s00340-0166502-0, 2016.

Romanini, D., Chenevier, M., Kassi, S., Schmidt, M., Valant, C., Ramonet, M., Lopez, J., and Jost, H.-J.: Optical-feedback cavityenhanced absorption: a compact spectrometer for real-time measurement of atmospheric methane, Appl. Phys. B, 83, 659-667, doi:10.1007/s00340-006-2177-2, 2006.

Rothman, L., Gordon, I., Babikov, Y., Barbe, A., Chris Benner, D., Bernath, P., Birk, M., Bizzocchi, L., Boudon, V., Brown, L., Campargue, A., Chance, K., Cohen, E., Coudert, L., Devi, V., Drouin, B., Fayt, A., Flaud, J.-M., Gamache, R., Harrison, 
J., Hartmann, J.-M., Hill, C., Hodges, J., Jacquemart, D., Jolly, A., Lamouroux, J., Le Roy, R., Li, G., Long, D., Lyulin, O., Mackie, C., Massie, S., Mikhailenko, S., Müller, H., Naumenko, O., Nikitin, A., Orphal, J., Perevalov, V., Perrin, A., Polovtseva, E., Richard, C., Smith, M., Starikova, E., Sung, K., Tashkun, S., Tennyson, J., Toon, G., Tyuterev, V., and Wagner, G.: The HITRAN2012 molecular spectroscopic database, J. Quant. Spectrosc. Ra., 130, 4-50, doi:10.1016/j.jqsrt.2013.07.002, 2013.

Sahu, L. K., Sheel, V., Kajino, M., and Nedelec, P.: Variability in tropospheric carbon monoxide over an urban site in Southeast Asia, Atmos. Environ., 68, 243-255, doi:10.1016/j.atmosenv.2012.11.057, 2013.

Schmidt, M., Lopez, M., Yver Kwok, C., Messager, C., Ramonet, M., Wastine, B., Vuillemin, C., Truong, F., Gal, B., Parmentier, E., Cloué, O., and Ciais, P.: High-precision quasi-continuous atmospheric greenhouse gas measurements at Trainou tower (Orléans forest, France), Atmos. Meas. Tech., 7, 2283-2296, doi:10.5194/amt-7-2283-2014, 2014.

Tans, P. and Zellweger, C.: 18th WMO/IAEA Meeting on Carbon Dioxide, Other Greenhouse Gases and Related Tracers Measurement Techniques (GGMT-2015), 229, available at: http://www.wmo.int/pages/prog/arep/gaw/documents/ FINAL_GAW_REPORT_229.pdf (last access: 12 May 2017), 2016.

Té, Y., Jeseck, P., Franco, B., Mahieu, E., Jones, N., Paton-Walsh, C., Griffith, D. W. T., Buchholz, R. R., Hadji-Lazaro, J., Hurtmans, D., and Janssen, C.: Seasonal variability of surface and column carbon monoxide over the megacity Paris, high-altitude Jungfraujoch and Southern Hemispheric Wollongong stations, Atmos. Chem. Phys., 16, 10911-10925, doi:10.5194/acp-1610911-2016, 2016.

Ventrillard-Courtillot, I., Gonthiez, T., Clerici, C., and Romanini, D.: Multispecies breath analysis faster than a single respiratory cycle by optical-feedback cavity-enhanced absorption spectroscopy, J. Biomed. Opt., 14, 064026, doi:10.1117/1.3269677, 2009.

Voulgarakis, A., Naik, V., Lamarque, J.-F., Shindell, D. T., Young, P. J., Prather, M. J., Wild, O., Field, R. D., Bergmann, D., CameronSmith, P., Cionni, I., Collins, W. J., Dalsøren, S. B., Doherty, R. M., Eyring, V., Faluvegi, G., Folberth, G. A., Horowitz, L. W., Josse, B., MacKenzie, I. A., Nagashima, T., Plummer, D. A., Righi, M., Rumbold, S. T., Stevenson, D. S., Strode, S. A., Sudo, K., Szopa, S., and Zeng, G.: Analysis of present day and future $\mathrm{OH}$ and methane lifetime in the ACCMIP simulations, Atmos. Chem. Phys., 13, 2563-2587, doi:10.5194/acp-13-25632013, 2013.
Warner, J., Carminati, F., Wei, Z., Lahoz, W., and Attié, J.-L.: Tropospheric carbon monoxide variability from AIRS under clear and cloudy conditions, Atmos. Chem. Phys., 13, 12469-12479, doi:10.5194/acp-13-12469-2013, 2013.

Worden, H. M., Deeter, M. N., Frankenberg, C., George, M., Nichitiu, F., Worden, J., Aben, I., Bowman, K. W., Clerbaux, C., Coheur, P. F., de Laat, A. T. J., Detweiler, R., Drummond, J. R., Edwards, D. P., Gille, J. C., Hurtmans, D., Luo, M., MartínezAlonso, S., Massie, S., Pfister, G., and Warner, J. X.: Decadal record of satellite carbon monoxide observations, Atmos. Chem. Phys., 13, 837-850, doi:10.5194/acp-13-837-2013, 2013.

Xueref-Remy, I., Messager, C., Filippi, D., Pastel, M., Nedelec, P., Ramonet, M., Paris, J. D., and Ciais, P.: Variability and budget of $\mathrm{CO}_{2}$ in Europe: analysis of the CAATER airborne campaigns - Part 1: Observed variability, Atmos. Chem. Phys., 11, 56555672, doi:10.5194/acp-11-5655-2011, 2011.

Yver, C.: Estimation des sources et puits du dihydrogène troposphérique : développements instrumentaux , mesures atmosphériques et assimilation variationnelle, $\mathrm{PhD}$ thesis, Université de Versailles, 2010.

Yver, C., Schmidt, M., Bousquet, P., Zahorowski, W., and Ramonet, M.: Estimation of the molecular hydrogen soil uptake and traffic emissions at a suburban site near Paris through hydrogen, carbon monoxide, and radon-222 semicontinuous measurements, J. Geophys. Res., 114, D18304, doi:10.1029/2009JD012122, 2009.

Yver Kwok, C., Laurent, O., Guemri, A., Philippon, C., Wastine, B., Rella, C. W., Vuillemin, C., Truong, F., Delmotte, M., Kazan, V., Darding, M., Lebègue, B., Kaiser, C., Xueref-Rémy, I., and Ramonet, M.: Comprehensive laboratory and field testing of cavity ring-down spectroscopy analyzers measuring $\mathrm{H} 2 \mathrm{O}, \mathrm{CO} 2, \mathrm{CH} 4$ and CO, Atmos. Meas. Tech., 8, 3867-3892, doi:10.5194/amt-83867-2015, 2015.

Zellweger, C., Steinbacher, M., and Buchmann, B.: Evaluation of new laser spectrometer techniques for in-situ carbon monoxide measurements, Atmos. Meas. Tech., 5, 2555-2567, doi:10.5194/amt-5-2555-2012, 2012. 